\title{
EMPREENDEDORISMO INFORMAL DIGITAL E SOCIAL COMMERCE NO NORDESTE BRASILEIRO: Um modelo de negócios no INSTAGRAM
}

\section{DIGITAL SHADOW ENTREPRENEURSHIP AND SOCIAL COMMERCE IN NORTHEAST OF BRAZIL: A model of business in the INSTAGRAM}

\author{
Raisa Teixeira Santana ${ }^{1}$ \\ Ludmilla Meyer Montenegro²
}

\begin{abstract}
RESUMO
O empreendedorismo informal digital abrange atividades econômicas no ambiente virtual $O$ empreendedorismo informal digital envolve atividades econômicas no ambiente virtual como as redes sociais virtuais e que não são reguladas pelas autoridades públicas. Assim, as atividades econômicas que ocorrem nessas plataformas sociais são denominadas social commerce. Este artigo objetiva averiguar o empreendedorismo informal digital por meio do Instagram no Nordeste. O estudo tem natureza qualitativa e é do tipo exploratório e descritivo. Os dados foram coletados por meio de entrevistas semiestruturadas e observação nãoparticipante e foram analisados por meio da análise de conteúdo. Os resultados da investigação indicam que os perfis dos donos de negócio não são tão distintos. Motivações como facilidade para acesso de novos mercados, aumento da exposição dos produtos e oportunidade estão entre as mais citadas. Já as dificuldades mais abordadas foram conseguir seguidores, somente visão e audição (som) podem ser utilizadas e funcionalidades ruins. Assim, o s-commerce é algo recente, não sendo possível afirmar se a realidade encontrada nesta pesquisa irá prevalecer com o passar dos anos.
\end{abstract}

Palavras-chave: Empreendedorismo Informal Digital. Social Commerce. Instagram.

\begin{abstract}
Informal digital entrepreneurship encompasses economic activities in the virtual environment, such as virtual social networks, which are not regulated by public authorities. In this context, the economic activities that occur in these social platforms are called social commerce. This research aims to investigate digital informal entrepreneurship through Instagram in the northeast. The study has a qualitative nature and is exploratory and descriptive. Data were collected through semi-structured interviews and non-participant observation and analyzed through content analysis. The research results indicate that the profiles of business owners are not so different. Motivations such as ease of access to new markets, increased exposure of products and opportunity are among the most cited. The difficulties most addressed were to achieve followers, only vision and sound can be used and bad functionalities. Thereby, scommerce is a recent phenomenon and it is not possible to say whether the reality found in this research will prevail over the years.
\end{abstract}

\footnotetext{
${ }^{1}$ Doutora em Administração pela Universidade Federal do Paraná. Professora na Universidade Federal de Sergipe. E-mail: ra.iii.sats@gmail.com

${ }^{2}$ Doutora em Administração pela Universidade Federal do Paraná. Professora na Universidade Federal de Sergipe. E-mail : ludmilla2907@gmail.com
} 
Keywords: Digital Shadow Entrepreneurship. Social Commerce. Instagram

JEL: M10, O17, O33..

\section{INTRODUÇÃO}

As atividades empreendedoras têm papel importante na economia dos países e podem ser representadas por ações individuais que objetivam o lucro econômico, havendo a possibilidade de geração de empregos. Nesse cenário, as ações empreendedoras podem ser formais ou informais, digitais ou não.

Ao combinar o empreendedorismo informal com o digital tem-se um ambiente on-line com atividades econômicas que não são reguladas por autoridades públicas. Nesse cenário, os principais canais em que esse tipo de empreendedorismo se localiza são os e-shops, sites e redes sociais virtuais (GASPARÉNIENÉ et al., 2017), como o Instagram.

Latiff e Safiee (2015) pontuam que os negócios existentes no Instagram estão praticamente fora do radar, apesar de gerar vendas equivalentes a um negócio de comércio eletrônico tradicional. Todavia, apesar da representatividade do Instagram no dia a dia das pessoas, a maioria dos estudos acadêmicos explora o Facebook (VISENTINI; BOBSIN; CHAGAS, 2015). Nesse contexto, aumenta-se a importância de pesquisas realizadas em uma rede social virtual diferente. Além disso, segundo Latiff e Safiee (2015), com o advento do smartphone, o Instagram tem ganhado popularidade e se tornado a principal escolha para os aspirantes a donos de negócios.

Outro fator que contribuiu para a escolha do Instagram para esta investigação é que, ao se levar em consideração a perspectiva dos usuários, foi identificado na investigação de Phua, Jin e Kim (2016) que quando se trata de seguir marcas, os usuários preferem utilizar o Instagram (38\%), no lugar do Facebook $(30,5 \%)$ e do Twitter (19,7\%).

A evolução do comércio eletrônico na economia digital tem levado a um paradigma denominado social commerce que nas palavras de Zhou, Zhang e Zimmermann (2013) envolve o uso de mídias baseadas na internet que permitem que as pessoas participem de inúmeras atividades como venda, compra e compartilhamento de produtos e serviços no mercado on-line e off-line.

É importante frisar que o empreendedorismo digital não é mais algo exclusivo dos tecnófilos (HULL et al., 2007) e apesar de sua relevância contemporânea, as pesquisas existentes em empreendedorismo têm negligenciado o papel das tecnologias digitais, havendo um esforço limitado em teorizar o papel de aspectos específicos das tecnologias que moldam as oportunidades, decisões, ações e resultados empreendedores (NAMBISAN, 2017).

Fischer e Reuber (2011) afirmam que o ambiente digital pode ajudar empreendedores a criar e capitalizar oportunidades. Nesse cenário, a fusão das mídias sociais e do comércio eletrônico fornece aos empreendedores a oportunidade de criar vitrines de seus produtos e serviços para o mundo, por meio de perfis em sites de redes sociais (SOUZA; SCHOEFFEL, 2013), podendo aumentar a quantidade de potenciais clientes (HUNG; YU; CHIU, 2018).

Apesar do grande potencial percebido, os poucos estudos que exploram o scommerce focam nas capacidades e papeis da mídia social, deixando de lado a 
perspectiva do modelo de negócio, bem como de um framework que poderia fornecer um modelo de s-commerce para guiar sua adoção (BAGHDADI, 2013).

Contudo, há alguns pontos fracos que o empreendedor digital deve levar em consideração antes de adotar o social commerce como: falta de controle da imagem (PARAÍSO, 2011), ter somente a visão e o som no momento da venda (LATIFF; SAFIEE, 2015), etc. Mesmo assim, já existem evidências do crescimento do uso de redes sociais virtuais, como o Instagram, pelos empreendedores.

Considerando que os empreendimentos informais estão se modificando devido ao desenvolvimento de tecnologias como as mídias sociais e oportunizando a criação de modelos de negócio com base nessas infraestruturas digitais, o presente trabalho tem como objetivo averiguar o empreendedorismo informal digital por meio do Instagram no Nordeste.

A presente investigação, ao focar no empreendedorismo informal digital no Instagram, pretende preencher uma lacuna identificada na literatura que se relaciona ao número cada vez maior de e-empreendimentos informais, nessa mídia social, em segmentos como moda e alimentação, por exemplo, e ausência de pesquisas que buscam entender esse modelo de negócio.

Ao realizar esta pesquisa, pretende-se entender esse mundo criado a partir do advento da web 2.0 e como os e-empreendedores informais estão lidando com ele. Nesse cenário, esta investigação é de importância para os indivíduos que estão interessados em adentrar nesta realidade, pois talvez seja possível prover a oportunidade de entender melhor alguns aspectos relacionados a esse modelo de negócio.

\section{O EMPREENDEDORISMO INFORMAL DIGITAL E O SOCIAL COMMERCE}

Para Gasparènienè e Remeikiene (2015), um dos principais problemas da última década é a dificuldade de se definir as atividades econômicas, os sujeitos e os objetos presentes no espaço virtual que é formado por redes sociais virtuais, por sistemas de negócios on-line, jogos de computadores, etc. Estes são locais onde o dinheiro circula, porém, as transações não geram um retorno para o governo.

As diferentes interpretações existentes em relação ao que é a economia informal digital - objetivo, objeto, natureza - fazem com que conceitos variados existam na literatura (GASPARÉNIENĖ; REMEIKIENE, 2015). Gasparènienè et al. (2016) se referem à economia informal digital como as atividades lucrativas on-line relacionadas ao comércio ou ao fornecimento de serviços e que não são registradas.

Pelas palavras de Gasparènienè e Remeikiene (2015), entende-se que o empreendedorismo informal recebe a designação de digital devido ao ambiente em que ocorre, migrando das ruas das cidades para o mundo criado com o advento da internet.

Diante do que foi exposto, gera-se a necessidade de entender o que diferencia a forma tradicional da digital dos empreendimentos informais. O Quadro 1 traz alguns pontos relevantes sobre esta diferenciação. 


\begin{tabular}{l} 
Quadro 1. Empreendedorismo informal tradicional X Empreendedorismo \\
informal digital \\
\begin{tabular}{|c|c|c|}
\hline Variável & $\begin{array}{c}\text { Empreendedorismo Informal } \\
\text { Tradicional }\end{array}$ & Empreendedorismo Informal Digital \\
\hline $\begin{array}{c}\text { Forma de } \\
\text { Pagamento }\end{array}$ & Dinheiro. & $\begin{array}{c}\text { Dinheiro eletrônico, sistemas de } \\
\text { pagamento on-line e transações } \\
\text { financeiras escondidas. }\end{array}$ \\
\hline Funções & $\begin{array}{c}\text { Marketing, principalmente por } \\
\text { meio do boca a boca, e canais } \\
\text { de distribuição. }\end{array}$ & $\begin{array}{c}\text { Produtos e serviços estão posicionados } \\
\text { on-line e, em alguns casos, envolvem } \\
\text { até mesmo centros de suporte. }\end{array}$ \\
\hline Segmento & $\begin{array}{c}\text { Local e com definição de um } \\
\text { segmento alvo. }\end{array}$ & $\begin{array}{c}\text { Internacional e auto segmentado. } \\
\text { Lucro. }\end{array}$ \\
\hline Objetivo & Lucro, recursos digitais valiosos e banco \\
de dados.
\end{tabular} \\
\hline
\end{tabular}

Fonte: Gasparènienè e Remeinieke (2015).

Gasparènienè e Remeinieke (2015) deixam evidente que as tecnologias digitais tornaram a economia informal mais abrangente, o que pode atrair tanto vendedores quanto consumidores. Apesar de tratar-se de negócios existentes no ambiente virtual, as motivações para iniciar tais atividades informais podem ser as mesmas dos negócios tradicionais como, por exemplo, necessidade (GODFREY, 2011), oportunidade (GODFREY, 2011), altas taxas tributárias (SCHNEIDER; BUEHN, 2015), desemprego (PASCHOAL et al., 2013), etc.

Nesse cenário, os principais canais em que o empreendedorismo informal digital se localiza são os e-shops, sites e redes sociais virtuais (GASPARÉNIENÉ; REMEIKIENE; SCHNEIDER, 2017). Eles também afirmam que $20 \%$ dos consumidores que fizeram parte da pesquisa compram produtos ou serviços de vendedores que operam em plataformas sociais.

Segundo Latiff e Safiee (2015), foi demonstrado que o Instagram é a melhor plataforma para os aspirantes a donos de negócio iniciar seus empreendimentos antes de decidir aventurar-se no mundo off-line. Desse modo, o Instagram tem o importante papel de moldar a forma como os negócios em casa constroem estratégias impactantes. Golbeck (2015) o define como uma rede social virtual de compartilhamento de fotos bastante popular entre adolescentes e adultos jovens.

O Instagram (2018a) divulgou em seu site que possui em média 800 milhões de usuários ativos mensalmente, 500 milhões de pessoas que o usam diariamente e que um total de 250 milhões de postagens na ferramenta stories (história) são realizadas por dia. Tais postagens caracterizam-se pelo desaparecimento da imagem ou do vídeo após um período de 24 horas.

Os brasileiros embarcam nas novidades bastante rápido e já são um dos principais produtores de conteúdo, sejam eles fotos ou vídeos, para a ferramenta stories (SANCHEZ, 2017). A pesquisa da Iska Digital publicada pela AdNews (2015) constatou que dos 16 milhões de usuários brasileiros à época da investigação, 6,3 milhões eram homens e 9,7 milhões eram mulheres.

Nesse âmbito, as atividades comerciais que ocorrem em redes sociais virtuais são denominadas social commerce (ZHOU; ZHANG; ZIMMERMANN, 2013) ou comércio social.

O social commerce, de acordo com Busalim e Hussin (2016), apresenta algumas características que o diferenciam do comércio eletrônico tradicional como a interatividade, a colaboração, a comunidade e o aspecto social. Tais características demonstram que a confiança, os comentários, referências e testemunhos de outros 
usuários exercem influência ao se realizar uma compra por meio dessa modalidade, conforme constatado na pesquisa de Hajli (2013). negócio.

O Quadro 2 apresenta as vantagens e as desvantagens desse modelo de

\section{Quadro 2. As vantagens e desvantagens do social commerce}

\begin{tabular}{|c|c|c|c|}
\hline Vantagens & Autores & Desvantagens & Autores \\
\hline $\begin{array}{l}\text { Economia dos custos } \\
\text { de transação }\end{array}$ & $\begin{array}{c}\text { Hajli (2013), Genç e } \\
\text { Öksüz (2015) e Hung, Yu } \\
\text { e Chiu (2018). }\end{array}$ & $\begin{array}{l}\text { Falta de controle da } \\
\text { imagem }\end{array}$ & $\begin{array}{l}\text { Demailly }(2008) \text { e } \\
\text { Paraíso (2011). }\end{array}$ \\
\hline $\begin{array}{l}\text { Aumento da interação } \\
\text { com o consumidor }\end{array}$ & $\begin{array}{c}\text { Afrasiabi Rad e } \\
\text { Benyoucef (2011), Genç e } \\
\text { Öksüz (2015), Erdoğmuş } \\
\text { e Tatar (2015) e Hung, Yu } \\
\text { e Chiu (2018). }\end{array}$ & $\begin{array}{c}\text { Vendas que dependem } \\
\text { de terceiros }\end{array}$ & $\begin{array}{l}\text { Lindsey-Mullikin e } \\
\text { Borin (2017). }\end{array}$ \\
\hline $\begin{array}{l}\text { Aumento da exposição } \\
\text { do produto }\end{array}$ & $\begin{array}{c}\text { Zhou, Zhang e } \\
\text { Zimmermann (2013), } \\
\text { Souza e Schoeffel (2013) } \\
\text { e Genç e Öksüz (2015). }\end{array}$ & $\begin{array}{l}\text { Simplicidade do modelo } \\
\text { de negócio }\end{array}$ & Kim (2013). \\
\hline Seguir tendências & Genç e Öksüz (2015). & $\begin{array}{l}\text { Perda do apelo das } \\
\text { redes sociais virtuais }\end{array}$ & $\begin{array}{l}\text { Wang e Zhang } \\
\text { (2012). }\end{array}$ \\
\hline $\begin{array}{l}\text { Apresentação de } \\
\text { porfólio }\end{array}$ & Genç e Öksüz (2015). & $\begin{array}{c}\text { Público alvo não } \\
\text { identificado }\end{array}$ & $\begin{array}{c}\text { Genç e Öksüz } \\
\text { (2015). }\end{array}$ \\
\hline \multirow[t]{5}{*}{$\begin{array}{l}\text { Aumento do volume } \\
\text { de vendas }\end{array}$} & \multirow[t]{5}{*}{ Hung, Yu e Chiu (2018). } & Competição não é justa & $\begin{array}{l}\text { Kim (2013) e } \\
\text { Genç e Öksüz } \\
\text { (2015). }\end{array}$ \\
\hline & & $\begin{array}{c}\text { Diminuição da fatia de } \\
\text { mercado }\end{array}$ & $\begin{array}{c}\text { Genç e Öksüz } \\
\text { (2015). }\end{array}$ \\
\hline & & $\begin{array}{c}\text { Imitação de produtos e } \\
\text { serviços }\end{array}$ & $\begin{array}{c}\text { Genç e Öksüz } \\
(2015) .\end{array}$ \\
\hline & & $\begin{array}{c}\text { Somente a visão e o } \\
\text { som }\end{array}$ & $\begin{array}{c}\text { Latiff e Safiee } \\
\text { (2015). }\end{array}$ \\
\hline & & Competição por preços & $\begin{array}{l}\text { Cozer (2007), Kim } \\
\text { (2013), Gerç e } \\
\text { Öksüz (2015). }\end{array}$ \\
\hline & & Conseguir seguidores & $\begin{array}{l}\text { Latiff e Safiee } \\
(2015)\end{array}$ \\
\hline
\end{tabular}

Fonte: elaborado pelas autoras (2018).

Percebe-se que os pontos positivos mais citados foram o aumento da interação com o consumidor e o aumento da exposição do produto. No contexto do social commerce, Erdoğmuş e Tatar (2015) discorrem que os estímulos para atrair e reter o consumidor originam-se por meio das campanhas de vendas, personalização, interatividade e conteúdo gerado pelo usuário sobre a marca sob a forma de referências, revisões e testemunhos, o que refletem no engajamento do consumidor com a organização em suas mídias sociais.

Já sobre as desvantagens, percebe-se que a falta de controle da imagem foi a desvantagem mais abordada, entretanto, parece não haver um consenso sobre os obstáculos desse modelo de negócio. Para Hung, Yu e Chiu (2018), os sites de redes sociais estão desenvolvendo plataformas amigáveis para o comércio, a fim de que os pequenos vendedores consigam negociar nessa rede. 


\section{METODOLOGIA}

Considerando que o objetivo desta investigação é averiguar o empreendedorismo informal digital por meio do Instagram no Nordeste, optou-se por uma abordagem qualitativa porque acredita-se que seja a que melhor atende ao problema definido para a pesquisa. Além disso, essa abordagem objetiva explorar as diferentes opiniões e representações sobre o tema tratado (GASKELL, 2002).

Esta pesquisa classifica-se como exploratória, visto que há pouco conhecimento acumulado e sistematizado sobre os empreendedores informais digitais no Instagram e também pode ser rotulada como descritiva já que nesta investigação houve a tentativa de expor determinadas características dos informantes-chave, bem como de seus relacionamentos (VERGARA, 2009).

Para esta investigação, utilizou-se como critérios de escolha das unidades de análise: a) o e-empreendimento deve ser informal e, para esta pesquisa, utilizou-se o mesmo critério do SPC Brasil (2013), ou seja, são os que não possuem CNPJ; b) ser do segmento de vestuário; c) atuar de modo informal há no mínimo 3 (três) meses no Instagram; d) o empreendimento deve estar localizado somente no Instagram, ou seja, não possuir um estabelecimento físico para atender seus clientes; e) o perfil da empresa deve possuir, no mínimo, 500 seguidores.

O critério "a" justifica-se em virtude de ser um dos recortes principais da temática abordada nesta investigação. O critério "b" foi escolhido como uma forma de limitar a investigação a um determinado segmento e o de vestuário foi escolhido, visto que, de acordo com a Associação Brasileira de Vestuário (ABRAVEST) (2018), aumentou bastante o número de empresas que vendem vestuário do varejo e porque, segundo Gasparènienè et al. (2017), roupas e calçados são os produtos mais vendidos (27\%) na economia informal digital. O critério "c" foi adicionado tendo-se em mente que empreendedores informais digitais com menos de 3 (três) meses da criação do perfil e, consequentemente, do estabelecimento podem não ter as respostas para os questionamentos desta pesquisa. O critério "d" também foi escolhido em razão de ser um recorte importante da pesquisa por se tratar especificamente daqueles empreendedores que possuem somente o Instagram como canal para empreender. Por fim, quanto ao critério "e", justifica-se que um perfil com no mínimo 500 seguidores tem a possibilidade de dispor de uma boa quantidade de clientes, levando-se em consideração que nem todos os usuários que seguem algum perfil comercial têm interesse em comprar algo.

Antes da escolha das unidades de análise que compuseram a pesquisa e entrar em contato com os empreendedores informais digitais, foi feita uma entrevista com uma das unidades de análise, que foi incorporada a esta pesquisa. Os critérios para a seleção do empreendedor da entrevista piloto foram os mesmos das demais unidades de análise.

Assim, realizou-se uma entrevista com indivíduos que residem na região Nordeste utilizando, sempre que necessário, recursos tecnológicos. Nos casos que foram necessários, a pesquisadora entrou em contato novamente com os entrevistados para dirimir dúvidas que a entrevista gerou ou para pedir informações adicionais. Aqui, a entrevista semiestruturada foi escolhida e foi realizada com os eempreendedores informais visto que, de acordo com Gray (2012), permite-se que se faça perguntas de aprofundamento.

Para esta pesquisa, foram realizadas 15 entrevistas com indivíduos que residem na região Nordeste que possuem uma loja no Instagram. Esse quantitativo 
foi emergindo no decorrer da pesquisa em virtude das informações coletadas estarem apresentando redundância. Dessa forma, a regra da saturação se fez presente.

Para compor o grupo dos informantes-chave, as pesquisadoras entraram em contato com donos de negócio que já conheciam, receberam indicações de entrevistados e procuraram perfis comerciais no Instagram por intermédio da aba de pesquisa, utilizando palavras-chave como blusa, $t$-shirt, crochê, lingerie, biquíni, praia, etc.

Após o primeiro contato com os informantes-chave utilizando Instagram ou WhatsApp, foi marcada a entrevista. A duração das entrevistas oscilou entre 20 minutos e 58 segundos e 57 minutos e 48 segundos e algumas foram gravadas no smartphone e outras com o notebook, visto que o celular estava sendo utilizado na ligação telefônica quando os entrevistados eram de outros estados.

Outra técnica para coleta de dados utilizada foi a observação não participante dos perfis do Instagram desses negócios para obter informações que os indivíduos não têm consciência que possuem, permitindo a coleta de dados sobre atitudes comportamentais típicas (MARCONI; LAKATOS, 2017).

A observação não participante, nesta investigação, objetivou acompanhar as postagens realizadas pelos empreendedores pesquisados e a troca de mensagens com clientes e/ou fornecedores que foram realizadas por meio da ferramenta comentários presente na rede social virtual pesquisada. Para o registro das observações, foi elaborada uma planilha contendo o nome da empresa, quantidade de postagens, do que se trata a postagem, quantidade de curtidas, quantidade de comentários, do que se tratavam esses comentários, quantidade de stories postados e observações sobre esses stories.

Nesse âmbito, duas vezes (ou mais) ao dia foi feito um acompanhamento dos perfis comerciais que consistiu, em um primeiro momento, na visualização das atividades públicas - citadas acima - e, ao final do dia, uma planilha foi alimentada com todas as informações pertinentes.

No início, o tempo gasto com as observações era reduzido, visto que poucos donos de negócio foram entrevistados. Todavia, quando o período das entrevistas encerrou, havia 14 empresas para serem acompanhadas - o período de observação do caso piloto estava encerrado. Assim, no começo eram gastos 20 minutos a 30 minutos por dia com as observações e no ápice o tempo variou entre 1 hora e 1 hora e 30 minutos diariamente, excluindo-se o tempo gasto para o preenchimento da planilha que oscilou entre 1 a 2 horas diárias.

Ressalta-se que todos os indivíduos que participaram da pesquisa o fizeram de forma voluntária, com a assinatura do Termo de Consentimento Livre e Esclarecido, que foi assinado pelos donos de cada empreendimento informal digital após a explicação da presente pesquisa.

Como forma de responder ao problema de pesquisa proposto, optou-se pela análise de conteúdo, pois ela, de acordo com Bardin (2011), permite uma combinação entre objetividade, sustentada por processos técnicos de validação, e subjetividade, presente na atitude interpretativa, que foi importante para compreender os achados desta pesquisa. Para auxiliar em todo esse processo, escolheu-se o software MAXQDA® que pôde ser utilizado para transcrições de entrevistas, análise de textos, etc, além de suportar vários tipos de arquivos como, por exemplo, de áudio, de texto, de tabelas, etc.

É importante ressaltar que somente os dados coletados por meio das entrevistas foram submetidos à análise de conteúdo. Dessa forma, a conversa com 
os entrevistados foi gravada, como abordado anteriormente, e depois transcrita e codificada utilizando o software MAXQDA® que permitiu que as atividades mais operacionais fossem realizadas de modo mais rápido e fácil.

\section{ANÁLISE E DISCUSSÃO DOS DADOS}

Nesta seção é apresentada a análise dos dados coletados nas 15 entrevistas realizadas com os donos de negócios do Instagram, bem como das observações realizadas durante 30 dias contados a partir do dia do encontro. A entrevista piloto, que está entre os 15 entrevistados, foi realizada no dia 08/04/2018 e as demais durante o período de 04/05/2018 a 15/05/2018.

Além disso, é realizada a discussão dos resultados encontrados neste estudo, à luz da literatura, como forma de comparar os resultados da pesquisa com o que foi estudado para compor a base teórica deste artigo. É preciso destacar que o número de empresas/empreendedores pesquisados não permite qualquer inferência que possa ultrapassar os próprios pesquisados.

Para manter a confidencialidade das informações coletadas, como também o nome dos entrevistados e de seus empreendimentos, foi criado o Quadro 4, no qual cada informante-chave recebeu um código relacionado ao produto vendido pela sua empresa. Por exemplo, a Empresa 1 revende peças femininas e por isso o seu respondente recebeu o código FEM1, a Empresa 4 trabalha com a venda de peças infantis, recebendo a participante o código INF4.

\section{Quadro 4. Informações dos informantes-chave}

\begin{tabular}{|l|l|l|}
\hline $\begin{array}{c}\text { Nome Fictício da } \\
\text { Empresa }\end{array}$ & \multicolumn{1}{|c|}{ Produtos Vendidos } & \multicolumn{1}{|c|}{$\begin{array}{c}\text { Nome Fictício do } \\
\text { Informante-Chave }\end{array}$} \\
\hline Empresa 1 & $\begin{array}{l}\text { Revenda de peças para mulheres como blusas, } \\
\text { vestidos, macaquinhos saias, shorts, tênis, bolsas e } \\
\text { chapéus. }\end{array}$ & FEM1 \\
\hline Empresa 2 & Blusas masculinas e femininas personalizadas. & UNI2 \\
\hline Empresa 3 & Jalecos masculinos e femininos personalizados. & CONF3 \\
\hline Empresa 4 & Revenda de roupas infantis masculinas e femininas & INF4 \\
\hline Empresa 5 & $\begin{array}{l}\text { Revenda de peças para mulheres como blusas, } \\
\text { vestidos, macaquinhos, saias, shorts, tênis, bolsas e } \\
\text { chapéus. }\end{array}$ & FEM5 \\
\hline Empresa 6 & Confecção de roupas femininas e infantis. & CONF6 \\
\hline Empresa 7 & Confecção de roupas femininas e infantis. & CONF7 \\
\hline Empresa 8 & Confeção de laços infantis. & INF8 \\
\hline Empresa 9 & Confecção de peças femininas e infantis em crochê. & CONF9 \\
\hline Empresa 10 & $\begin{array}{l}\text { Revenda de peças femininas como moda íntima, } \\
\text { moda praia, babydols e camisolas. }\end{array}$ & FEM10 \\
\hline Empresa 11 & Revenda de bodys. & FEM11 \\
\hline Empresa 12 & Confecção de peças femininas e infantis em crochê. & CONF12 \\
\hline Empresa 13 & Blusas femininas e masculinas personalizadas. & UNI13 \\
\hline Empresa 14 & $\begin{array}{l}\text { Revenda de peças femininas como moda íntima e } \\
\text { moda praia. }\end{array}$ & FEM14 \\
\hline Empresa 15 & Revenda de peças femininas, masculinas e infantis. & UNI15 \\
\hline
\end{tabular}

Fonte: elaborado pelas autoras com base nos dados coletados na pesquisa (2018).

No decorrer das análises, as informações foram descritas de acordo com o relato dos entrevistados e comparando as diversas ações e opiniões identificadas. Em alguns momentos, frases são citadas, como forma de evidenciar a opinião exata do entrevistado em relação ao assunto abordado. 


\section{Características do empreendedor nordestino}

Em um primeiro momento, foi perguntado aos entrevistados questões relacionadas à escolaridade, idade, sexo, estado civil, estado em que reside, se possuía outro negócio antes desse criado no Instagram, se possui outra fonte de renda, sobre sua jornada de trabalho, sobre o uso do Instagram, duração de cada acesso e o dispositivo mais utilizado. Nesta seção, são abordadas as respostas dos entrevistados para que se possa entender melhor quem são os informantes-chave desta pesquisa.

\section{Quadro 5. Perfil dos entrevistados}

\begin{tabular}{|c|c|c|c|c|c|}
\hline $\begin{array}{c}\text { Nome } \\
\text { Fictício do } \\
\text { Informante- } \\
\text { Chave }\end{array}$ & Escolaridade & $\begin{array}{l}\text { Faixa } \\
\text { Etária }\end{array}$ & Sexo & Estado Civil & $\begin{array}{l}\text { Estado em } \\
\text { que reside }\end{array}$ \\
\hline FEM1 & $\begin{array}{ll}\text { Ensino } & \text { Superior } \\
\text { Incompleto - Arquitetura e } \\
\text { Urbanismo }\end{array}$ & 18 & Feminino & Solteira & Sergipe \\
\hline UNI2 & Ensino Médio Completo & 22 & Masculino & Solteiro & Ceará \\
\hline CONF3 & $\begin{array}{ll}\text { Pós-Graduação } \\
\text { Odontologia }\end{array}$ & 27 & Feminino & Solteira & Sergipe \\
\hline INF4 & $\begin{array}{l}\text { Ensino Superior Completo } \\
\text { - Ciências Contábeis }\end{array}$ & 24 & Feminino & Casada & Sergipe \\
\hline FEM5 & $\begin{array}{ll}\text { Ensino } & \text { Superior } \\
\text { Incompleto - Arquitetura e } \\
\text { Urbanismo }\end{array}$ & 22 & Feminino & Solteira & Sergipe \\
\hline CONF6 & $\begin{array}{l}\text { Ensino Superior Completo } \\
\text { - Engenharia de Produção }\end{array}$ & 34 & Feminino & Casada & Sergipe \\
\hline CONF7 & $\begin{array}{l}\text { Ensino Superior Completo } \\
\text { - Serviço Social }\end{array}$ & 55 & Feminino & Divorciada & Sergipe \\
\hline INF8 & $\begin{array}{lll}\text { Pós- } & \text { Graduação } \\
\text { Odontologia }\end{array}$ & 44 & Feminino & Casada & Sergipe \\
\hline CONF9 & $\begin{array}{lc}\text { Ensino } & \text { Superior } \\
\text { Incompleto - Fisioterapia }\end{array}$ & 33 & Feminino & Casada & Alagoas \\
\hline FEM10 & $\begin{array}{l}\text { Ensino Superior Completo } \\
\text { - Pedagogia }\end{array}$ & 24 & Feminino & Solteira & Sergipe \\
\hline FEM11 & $\begin{array}{l}\text { Ensino } \\
\text { Incompleto - Arquitetura e } \\
\text { Urbanismo }\end{array}$ & 19 & Feminino & Solteira & Sergipe \\
\hline CONF12 & $\begin{array}{l}\text { Ensino Superior Completo } \\
\text { - Licenciatura em Letras }\end{array}$ & 31 & Feminino & Casada & Pernambuco \\
\hline UNI13 & $\begin{array}{l}\text { Ensino Superior Completo } \\
- \text { Gestão de Recursos } \\
\text { Humanos }\end{array}$ & 29 & Masculino & Solteiro & Bahia \\
\hline FEM14 & $\begin{array}{l}\text { Ensino Superior Completo } \\
\text { - Administração }\end{array}$ & 25 & Feminino & Solteira & Ceará \\
\hline UNI15 & $\begin{array}{lr}\text { Ensino } & \text { Superior } \\
\text { Incompleto }- & \text { Engenharia } \\
\text { Ambiental } & \end{array}$ & 21 & Feminino & Solteira & Bahia \\
\hline
\end{tabular}

Fonte: elaborado pelas autoras com base nos dados coletados na pesquisa (2018).

O Quadro 5 mostra que 10 dos informantes-chave possuem pelo menos o Ensino Superior Completo em diversas áreas como, por exemplo, odontologia, serviço social, arquitetura e urbanismo. Os outros 5 respondentes possuem pelo menos 0 
Ensino Médio Completo. Tais dados deixam claro que o empreendedor digital presente nesta pesquisa é diferente daquele abordado por Gomes (2003), pois, de acordo com ele, é mais comum encontrar empreendedores com conhecimento tecnológico aprofundado.

Com relação à faixa etária, 8 dos 15 participantes da pesquisa estão na faixa dos 20 aos 29 anos, o que está de acordo com as faixas etárias com a maior quantidade de usuários do Instagram identificadas pela AdNews (2015) que são de 18-25 anos e 26-35 anos. Quanto ao sexo, grande parte pertence ao sexo feminino (13) e com relação ao estado civil, observou-se que a maioria é solteiro (9), havendo somente um divorciado. Grande parte dos informantes-chave reside em Sergipe, havendo também representantes de outros estados nordestinos como Ceará, Bahia, Alagoas e Pernambuco.

Em resumo, as características encontradas nesta pesquisa foram distintas daquelas presentes em outras investigações sobre os empreendedores informais e sobre os digitais. Por exemplo, o SPC Brasil (2013) pontuou que 49,8\% eram do sexo feminino, $59 \%$ casados, a faixa etária mais significativa é formada por pessoas entre 35-49 anos e a maioria possui no máximo o Ensino Médio Completo e quanto às características do empreendedor digital brasileiro, o SEBRAE (2017) pontuou que ele é, em sua maioria, do sexo masculino (67\%), possui em média 26 anos e $50 \%$ possui Ensino Superior Completo.

Todavia, ao se levar em consideração a pesquisa de Hung, Yu e Chiu (2018) sobre os pequenos vendedores do social commerce em Taiwan, é possível perceber pontos em comum em relação ao perfil dos participantes de ambas as investigações. Os participantes da pesquisa (136) de Hung, Yu e Chiu (2018) são em sua maioria (104) do sexo feminino, possui Ensino Superior Completo (129) e a faixa etária mais representativa é composta por indivíduos entre 21-30 anos (107).

Assim, é possível perceber que para esta pesquisa, o perfil do empreendedor informal tradicional e o perfil do empreendedor digital são diferentes do empreendedor informal digital atuante em redes sociais virtuais. O Quadro 6 mostra outras características dos respondentes. 
Quadro 6. Características dos entrevistados

\begin{tabular}{|c|c|c|c|c|c|}
\hline $\begin{array}{c}\text { Nome } \\
\text { Fictício do } \\
\text { Informante- } \\
\text { Chave }\end{array}$ & $\begin{array}{c}\text { Possuía Outro } \\
\text { Empreendimento } \\
\text { Antes }\end{array}$ & $\begin{array}{c}\text { Outra } \\
\text { Fonte } \\
\text { de } \\
\text { Renda }\end{array}$ & $\begin{array}{c}\text { Jornada de } \\
\text { Trabalho }\end{array}$ & $\begin{array}{l}\text { Uso do } \\
\text { Instagram } \\
\text { por Dia }\end{array}$ & $\begin{array}{l}\text { Duração de } \\
\text { Cada } \\
\text { Acesso }\end{array}$ \\
\hline FEM1 & Não & Não & $24 / 7$ & 9 horas & 1 hora \\
\hline UNI2 & Não & Não & $24 / 7$ & 2 horas & 20 minutos \\
\hline CONF3 & Não & Sim & $\begin{array}{l}\text { Horário Comercial } \\
\text { na maioria das } \\
\text { vezes }\end{array}$ & 1 hora & 5 minutos \\
\hline INF4 & Não & Sim & $\begin{array}{l}\text { 24/7, mas não faz } \\
\text { entrega nos } \\
\text { horários } \\
\text { comerciais }\end{array}$ & 6 horas & 5 minutos \\
\hline FEM5 & Não & Sim & $24 / 7$ & $\begin{array}{l}\text { O dia todo, } \\
\text { não soube } \\
\text { especificar } \\
\text { quanto tempo }\end{array}$ & 40 minutos \\
\hline CONF6 & Não & Não & $\begin{array}{lr}\text { De } 7: 00 \text { às } & 12: 00 \\
\text { e de } 12: 30 \text { às } \\
\text { 17:00, } \\
\text { exceção r } & \text { com } \\
\text { domingos } & \\
\end{array}$ & 3 horas & $\begin{array}{l}\text { De } 15 \text { a } 30 \\
\text { minutos }\end{array}$ \\
\hline CONF7 & Sim & Não & $\begin{array}{lr}\text { De 8:00 às } & 12: 00 \\
\text { e de 14:00 às } \\
\text { 18:00, } \\
\text { exceção } & \text { com } \\
\text { domingos } & \text { dos }\end{array}$ & 4 horas & 20 minutos \\
\hline INF8 & Sim & Sim & $\begin{array}{l}\text { Á noite e nos } \\
\text { finais de semana }\end{array}$ & 40 minutos & 5 minutos \\
\hline CONF9 & Não & Não & $24 / 7$ & 3 horas & 30 minutos \\
\hline FEM10 & Sim & Sim & $\begin{array}{l}\text { Dias da semana e } \\
\text { manhãs de } \\
\text { sábado }\end{array}$ & 8 horas & 45 minutos \\
\hline FEM11 & Não & Não & $24 / 7$ & 8 horas & 30 minutos \\
\hline CONF12 & Não & Não & $\begin{array}{l}8: 00 \text { às } 12: 00 \text { e de } \\
14: 00 \text { às } 17: 00\end{array}$ & 5 horas & $\begin{array}{l}40 \text { minutos a } \\
1 \text { hora. }\end{array}$ \\
\hline UNI13 & Não & Não & $\begin{array}{l}\text { De 10:00 às } \\
\text { 18:00. }\end{array}$ & 8 horas & $\begin{array}{l}\text { Deixa } \\
\text { Instagram } \\
\text { sempre } \\
\text { aberto } \\
\text { quando } \\
\text { trabalha }\end{array}$ \\
\hline FEM14 & Sim & Sim & $24 / 7$ & 6 horas & 2 a 5 minutos \\
\hline UNI15 & Não & Não & $24 / 7$ & $\begin{array}{l}\text { O dia todo, } \\
\text { não soube } \\
\text { especificar } \\
\text { quanto tempo }\end{array}$ & $\begin{array}{l}10 \text { minutos, } \\
\text { no máximo. }\end{array}$ \\
\hline
\end{tabular}

Fonte: elaborado pelas autoras com base nos dados coletados na pesquisa (2018).

Em resumo, os informantes-chave CONF7 e INF8 possuíam ou possuem um negócio formal, enquanto a experiência de FEM10 e FEM14 é formada por atividades informais. É importante ressaltar que nenhuma das experiências anteriores dos informantes-chave consistiu em empresas on-line.

A maioria dos informantes-chave que possui mais de uma fonte de renda não têm intenção, até o momento, de abandonar seus empregos para se dedicar totalmente à loja do Instagram. Entre as motivações para essa atitude estão o receio 
do empreendimento não dar certo, pois eles veem essa atividade como algo volátil, sem uma espécie de estabilidade, e como uma renda extra.

Com relação à jornada de trabalho, Davidson e Vaast (2010) afirmam que uma das características de um empreendimento digital é a disponibilidade 7 dias por semana e 24 horas por dia. Hull et al. (2007) corroboram esse ponto ao afirmar que em um mercado digital, espera-se que o negócio esteja operando 24/7, o que está em sintonia com os informantes-chave FEM1, UNI2, INF4, FEM5, FEM11, FEM14 e UNI15 como mostram os seguintes trechos das entrevistas:

Eta... sempre, direto. Sempre quando tem direct eu respondo..., mas em questão de responder, a qualquer horário eu respondo. (FEM5)

À noite e nos finais de semana, qualquer horário, feriado, qualquer horário. (FEM11)

Com relação ao uso do Instagram, foi possível perceber que vários entrevistados passam 6 horas ou mais do seu dia utilizando a rede social virtual, o que representa uma parcela considerável do tempo do empreendedor. Corroborando esse ponto, Fischer e Reuber (2011) comentaram que as mídias sociais são responsáveis pela maior parte do uso da internet pelo fato de possuir engajamento em interações sociais em uma escala que antes era impossível.

Nesse âmbito, o dispositivo que tornou possível aos informantes-chave estarem, sempre que quiserem, conectados com sua loja virtual foi o celular. Nesta pesquisa, essa ferramenta mobile recebeu resposta unânime quanto ao dispositivo mais utilizado para acessar o Instagram e as justificativas para sua escolha também foram bastante similares.

Porque é uma ferramenta mais prática que a gente tem na mão assim. Porque notebook nem todo lugar que a gente vai, a gente tem acesso assim, leva. $\mathrm{E}$ o celular já é uma ferramenta que a gente anda, a gente nunca consegue sair de casa sem o celular, se esquecer o celular, volta pra pegar. (INF4)

Porque... a facilidade, porque tudo você faz ali no telefone, foto você já tá no telefone, tudo é no telefone (FEM5)

Corroborando os achados desta pesquisa, Golbeck (2015) pontua que um dos mais importantes aspectos do Instagram é que os dispositivos móveis são as principais vias de acesso. Assim, evidencia-se a necessidade de entender melhor 0 que motivou os informantes-chave a utilizar o Instagram como um canal para empreender.

\section{Motivações para iniciar o negócio}

Esta seção trata de apresentar os motivos que levaram os donos de negócio desta investigação a abrir uma loja no Instagram. Tais motivações foram retiradas da seguinte literatura: necessidade (GODFREY, 2011), oportunidade (GODFREY, 2011), hobby (GIACOMIN et al., 2011), altas cargas tributárias (WEBB et al., 2013), evitar padrões legais no mercado (PASCHOAL et al., 2013; SCHNEIDER; BUEHN, 2015) desemprego (SPC BRASIL, 2013), ser independente (SPC BRASIL, 2013), vontade de ter o próprio negócio (SPC BRASIL, 2013), flexibilidade de horário (SEBRAE, 2017), aumento da interação com o consumidor (GENÇ; ÖKSÜZ, 2015), aumento da exposição do produto (GENÇ; ÖKSÜZ, 2015), adesão de outras empresas ( surgiu na 
análise das entrevistas), custo reduzido do investimento (SEBRAE, 2017), custo reduzido da transação (GENÇ; ÖKSÜZ, 2015), facilidade para acesso de novos mercados (SEBRAE, 2017) e simplicidade do modelo de negócio ( surgiu na análise das entrevistas).

Nesse âmbito, Nambisan (2017) pontua que por se tratar de um processo empreendedor bastante dinâmico, no social commerce podem surgir atores com os mais diversos motivos e objetivos. Dessa forma, as motivações para tal foram diversas como mostra o Quadro 6. É importante destacar que os informantes-chave podem ter mais de um motivo para utilizar o Instagram como canal para empreender.

O Quadro 6 mostra que os informantes-chave que mais abordaram fatores que os motivaram a empreender por meio do Instagram foram FEM1 e CONF7 (9). FEM10 (4) foi a respondente que teve menos motivações para aderir a essa rede social virtual e grande parte (8) possui 7 ou 6 pontos motivadores. É importante ressaltar que a motivação simplicidade no modelo de negócio foi identificada no artigo de Kim (2013) como um ponto negativo, todavia, nesta pesquisa surgiu como uma motivação.

Com relação aos itens mais representativos nesta pesquisa tem-se, por ordem de frequência:

\section{Facilidade para acesso de novos mercados}

$\mathrm{Na}$ pesquisa desenvolvida por Gerç e Öksüz (2015), grande parte dos participantes afirmou que o Instagram é mais adequado como uma plataforma de negócios em virtude da possibilidade de se comunicar não somente com os conhecidos, mas também com pessoas que você não conhece. Em consonância com essa afirmação, FEM10 e FEM11 comentam que no mínimo metade de seus clientes são formados por pessoas que elas não conhecem, já CONF9 possui apenas clientes desconhecidos.

Gasparènienè e Remeikiene (2015) discorrem que a economia informal digital consegue abranger uma área geográfica muito maior do que a economia informal tradicional.

São Paulo, eu consigo mandar um jaleco daqui pra Minas, então o jaleco roda né, Sergipe, Bahia, eu faço entrega em vários lugares então assim, o negócio aumentou. (CONF3)

...cliente de Aracaju, de Recife, de Fortaleza, de Maceió, do Maranhão, eu enviava. (CONF6)

Tem peças minhas nos Estados Unidos, tem peças minhas na Espanha. Eu não vendo aqui em Maceió, em Maceió eu não tenho clientes, eu somente tenho clientes de fora do Estado...

No ambiente digital, um consumidor pode ser da Tunísia, o seguinte de Taipei, o próximo de Paris (HULL et al., 2007), fato é que os inúmeros desenvolvimentos tecnológicos e logísticos tornaram possível que pessoas que residam em qualquer local possam se comunicar.

\section{Aumento da exposição dos produtos}

Domingues et al. (2017) explicam que com o advento e ampliação de inúmeras ferramentas tecnológicas permitiu-se que fatores como a distância entre o cliente e a 
organização diminuíssem, possibilitando que os produtos ou serviços de uma organização pudessem ser expostos em qualquer lugar e a qualquer hora por meio de dispositivos móveis, principalmente o celular

\section{Quadro 61. Consolidação das motivações}

\begin{tabular}{|c|c|c|c|c|c|c|c|c|c|c|c|c|c|c|c|c|}
\hline Motivações & 1 & 2 & 3 & 4 & 5 & 6 & 7 & 8 & 9 & 10 & 11 & 12 & 13 & 14 & 15 & Total \\
\hline Necessidade & $\mathrm{X}$ & & & & $\mathrm{X}$ & $\mathrm{X}$ & $X$ & & $\mathrm{X}$ & $\mathrm{X}$ & & & & & & 6 \\
\hline Oportunidade & & $X$ & $X$ & $X$ & & & $\mathrm{X}$ & $\mathrm{X}$ & $\mathrm{X}$ & & $\mathrm{X}$ & & $\mathrm{X}$ & & $\mathrm{X}$ & 9 \\
\hline Hobby & & $\mathrm{X}$ & & & $\mathrm{X}$ & & & $\mathrm{X}$ & & & & $\mathrm{X}$ & & & & 4 \\
\hline $\begin{array}{l}\text { Altas cargas } \\
\text { tributárias }\end{array}$ & & & $\mathrm{X}$ & $X$ & & & $\mathrm{X}$ & $\mathrm{X}$ & $\mathrm{X}$ & $\mathrm{X}$ & & & & & $\mathrm{X}$ & 7 \\
\hline \begin{tabular}{|lr} 
Evitar & padrões \\
legais & do \\
mercado & \\
\end{tabular} & & & $\mathrm{X}$ & $\mathrm{X}$ & & & & & & & & & & & $\mathrm{X}$ & 3 \\
\hline Desemprego & & & & & & $X$ & & & $\mathrm{X}$ & $\mathrm{X}$ & & & & & & 3 \\
\hline Ser independente & $\mathrm{X}$ & & & & $\mathrm{X}$ & & & & & & $\mathrm{X}$ & & & & & 3 \\
\hline $\begin{array}{l}\text { Vontade de ter o } \\
\text { próprio negócio }\end{array}$ & $\mathrm{X}$ & & & & & & & & & & & & & $\mathrm{X}$ & & 2 \\
\hline $\begin{array}{l}\text { Flexibilidade de } \\
\text { horário }\end{array}$ & & & $\mathrm{X}$ & $\mathrm{X}$ & & & $\mathrm{X}$ & $\mathrm{X}$ & & & & & $\mathrm{X}$ & & & 5 \\
\hline $\begin{array}{l}\text { Aumento da } \\
\text { interação com o } \\
\text { consumidor }\end{array}$ & $\mathrm{X}$ & $x$ & & & & $x$ & $\mathrm{X}$ & & & & $\mathrm{X}$ & & $\mathrm{X}$ & $\mathrm{X}$ & & 7 \\
\hline 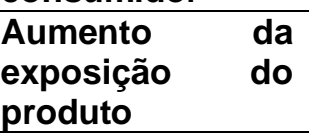 & $\mathrm{X}$ & $x$ & $\mathrm{X}$ & $X$ & $\mathrm{X}$ & $X$ & $X$ & $\mathrm{X}$ & & & $\mathrm{X}$ & $x$ & $\mathrm{X}$ & & $\mathrm{X}$ & 12 \\
\hline $\begin{array}{l}\text { Adesão de outras } \\
\text { empresas }\end{array}$ & $\mathrm{X}$ & & & $X$ & & & & & $X$ & $\mathrm{X}$ & $\mathrm{X}$ & $X$ & $\mathrm{X}$ & $\mathrm{X}$ & & 8 \\
\hline $\begin{array}{l}\text { Custo reduzido } \\
\text { do investimento }\end{array}$ & $\mathrm{X}$ & $X$ & & & $\mathrm{X}$ & & & & & & & & $\mathrm{X}$ & $\mathrm{X}$ & & 5 \\
\hline $\begin{array}{l}\text { Custo reduzido } \\
\text { da transação }\end{array}$ & $\mathrm{X}$ & & $\mathrm{X}$ & & & & $\mathrm{X}$ & & & & & & & & & 3 \\
\hline $\begin{array}{l}\text { Facilidade para } \\
\text { acesso de novos } \\
\text { mercados }\end{array}$ & $\mathrm{X}$ & $x$ & $\mathrm{X}$ & $\mathrm{X}$ & $X$ & $\mathrm{X}$ & $\mathrm{X}$ & $\mathrm{X}$ & $\mathrm{X}$ & & $\mathrm{X}$ & $\mathrm{X}$ & $X$ & $\mathrm{X}$ & $\mathrm{X}$ & 14 \\
\hline $\begin{array}{ll}\text { Simplicidade } & \text { do } \\
\text { modelo } & \text { de } \\
\text { negócio } & \\
\end{array}$ & & $X$ & & & & & $\mathrm{X}$ & & & & & & & & & 2 \\
\hline Total & 9 & 7 & 7 & 7 & 6 & 5 & 9 & 6 & 6 & 4 & 6 & 4 & 7 & 5 & 5 & 93 \\
\hline
\end{tabular}

Fonte: elaborado pelas autoras com base nos dados coletados na pesquisa (2018).

Não, eu sempre gostei de... tudo que eu posto no Instagram... assim pra mim é maravilhoso. Tipo, uma peça tá parada aqui, eu fiz um vestido, quando eu coloco no Instagram na mesma hora eu vendo, na mesma hora eu vendo. (CONF6)

Porque eu acho que hoje em dia a maior ferramenta de exposição é o Instagram. Que já é próprio pra postar fotos. É uma rede social que gira em torno disso. (UNI15)

Durante as entrevistas, ao falarem sobre o Instagram, alguns participantes também abordaram o Facebook com comentários relacionados ao declínio dessa rede social virtual como a primeira opção entre os usuários. 


\section{Oportunidade}

Muitos escolhem desenvolver suas atividades na economia informal baseados em valores conscientes, em vez de necessidade (GODFREY, 2011). Nesse cenário, estatisticamente, Williams (2009) indicou que $77 \%$ estão no setor informal por escolha.

...então os jalecos começaram a partir dos meus jalecos, então hoje eu tenho vários jalecos coloridos e aí quando as pessoas, quando os colegas começaram a ver que eu não usava mais o branco, que eu tinha o jaleco colorido aí eu falei ahh, é minha mãe que faz, se você quiser eu falo com ela e pergunto se ela pode fazer pra você um jaleco colorido. E aí foi surgindo, as pessoas foram falando ahh eu queria um jaleco assim que nem o seu colorido, aí eu disse olha... (CONF3)

\section{Adesão por outras empresas}

Essa motivação não está presente na literatura pesquisada para a realização desta pesquisa. Todavia, mais da metade (8) dos informantes-chave desta investigação pontuaram que a existência de inúmeras lojas no Instagram, muitas das quais alcançando sucesso, os incentivaram a utilizar esse canal para empreender.

Porque... é... exemplo de lojas virtuais nesse ramo de.... de ter um sucesso. (CONF9)

...porque eu não gosto de usar o Face, só uso o Instagram e como eu vejo que muitas lojas vendem pelo Instagram eu fui na onda né, segui o fluxo (risos). (FEM11)

\section{Aumento da interação com o consumidor}

No próprio conceito de mídias sociais, Abbas e Singh (2014) abordam a interação entre as pessoas que permite que elas criem, troquem e compartilhem informações e pensamentos. Nesta pesquisa, os respondentes que comentaram sobre o aumento da interação com o consumidor ser um ponto positivo foram FEM1, UNI2, CONF6, CONF7, FEM11, UNI13 e FEM14.

\footnotetext{
Porque o Instagram você posta, você conversa com eles ali no Instagram...(CONF6)

O meu relacionamento com as clientes é um relacionamento muito bom, porque a gente acaba não se tornando clientes e sim amigas. (FEM14)
}

\section{Altas cargas tributárias}

As cargas tributárias, para Paschoal et al. (2013), é um dos principais motivadores para a inserção no mercado informal. Nesta pesquisa, os entrevistados CONF3, INF4, CONF7, INF8, CONF9, FEM10 e UNI15 apontaram os tributos como um dos fatores que os influenciaram para empreender no Instagram.

...mas sempre foi assim, tipo, entra $17 \%$ na... quando entra no estado é $17 \%$ pra entrar mercadoria no estado de Sergipe, pra você vender é 3\% o simples quando for uma empresa pequena, aí já é $20 \%$. E nessa mercadoria que você 
comprou, entrou no estado a pessoa que lhe vendeu já pagou imposto também da saída. Então, você viu que gera tanto imposto. (INF4)

...loja física tem que entrar com aluguel, agua, luz, impostos, e eu vendendo pelo Instagram não tenho nada disso. (CONF9)

É possível perceber que os fatores motivadores identificados como os mais representativos nesta pesquisa foram retirados da literatura sobre 0 empreendedorismo informal, sobre o empreendedorismo digital e sobre o social commerce. Ademais, adesão por outras empresas foi um dos fatores motivadores mais abordados que influenciaram na utilização do Instagram como canal para empreender e que não está presente na literatura acadêmica.

E como nem tudo no Instagram é uma motivação para empreender, a próxima seção aborda as dificuldades encontradas pelos donos de negócio para comercializar nesse meio.

\section{Dificuldades para Empreender no Instagram}

Esta seção trata de conhecer as dificuldades enfrentadas pelos donos de negócio desta investigação ao abrir uma empresa no Instagram. Dessa forma, várias dificuldades foram identificadas como mostra o Quadro 7, com base na seguinte literatura: competição por preço (KIM, 2013), vendas que dependem de terceiros (LINDSEY-MULLIKIN, 2017), público-alvo não identificado (GENÇ; ÖKSÜZ, 2015), diminuição da fatia de mercado/imitação de produtos e serviços (GENÇ; ÖKSÜZ, 2015), somente visão e som (LATIFF; SAFIEE, 2015), funcionalidades ruins (surgiu na análise das entrevistas), experimentar peças em casa (surgiu na análise das entrevistas, conseguir seguidores (LATIFF; SAFIEE, 2015) e falta de domínio da ferramenta (CALAIS; SANTOS, 2016).

É importante ressaltar que cada informante-chave pode ter identificado mais de uma dificuldade para empreender utilizando esse canal.

O Quadro 7 mostra que o participante desta pesquisa que identificou mais dificuldades foi FEM1 e aqueles que tiveram menos dificuldades, apenas uma, foram UNI2, FEM10 e CONF12. Os informantes-chave FEM5, CONF7 e UNI15 alegaram não ter dificuldades para empreender no Instagram. Dessa forma, os obstáculos mais representativos encontrados nesta investigação foram:

\section{Conseguir seguidores}

Dois dos aspectos abordados anteriormente que motivaram os indivíduos a utilizar o Instagram como canal para empreender foi o aumento da exposição do produto e a facilidade para acessos a novos mercados. Todavia, antes de colher esses benefícios, é necessário ultrapassar uma dificuldade: conseguir seguidores.

UNI2, CONF3, INF4, INF8, FEM11, CONF12, UNI13 e FEM14 foram os informantes-chave que abordaram esse obstáculo. A seguir, tem-se os relatos de alguns deles:

A dificuldade do Instagram é você conseguir mais seguidores. Aí então você tem que ter uma forma de começar a seguir um monte de gente quando você tem tempo pra a pessoa botar pra a pessoa botar pra seguir você de novo... (INF4) 
A única dificuldade é tornar ela conhecida né, ter muitos seguidores... (FEM11)

Para superar esse obstáculo, os informantes-chave fazem uso das seguintes práticas: a) utilizar seus perfis pessoais do Instagram para iniciar o empreendimento por já possuírem uma boa quantidade de seguidores; b) gerenciadores de Instagram que seguem usuários e curte as fotos deles automaticamente; c) usar a ferramenta patrocinado do Instagram; d) realizar sorteios que consiste, geralmente, em seguir o perfil comercial que está sorteando o produto ou serviço e marcar alguns amigos nos comentários da postagem e e) contratam influenciadores digitais que são indivíduos que têm a capacidade de influenciar o comportamento das pessoas por meio das mídias sociais.

\section{Somente visão e som}

Ter somente a visão e o som no momento da venda é uma desvantagem do social commerce abordada por Latiff e Safiee (2015). Contudo, esse ponto negativo não é algo novo para o comércio eletrônico tradicional. Como as empresas que fazem parte desta pesquisa comercializam vestimentas, o ponto que recebeu destaque foi experimentar as peças. Os depoimentos que seguem ilustram esse cenário:

Até porque as pessoas perguntam: Tem loja física? Queria dar uma olhadinha, queria experimentar... (FEM1)

... a questão só é porque assim como eu não tenho as peças pra mostrar, as pessoas me cobram... tipo deixam de comprar por conta disso... (FEM11)

\section{Funcionalidades ruins}

O Instagram é atualizado frequentemente, seja para inserir novas funcionalidades, seja para melhorar as já existentes conseguindo, com o passar dos anos, conquistar cada vez mais usuários, contudo ainda há pontos que precisam ser melhorados. Funcionalidades ruins não é uma dificuldade presente na literatura pesquisada sobre o tema, todavia, FEM1, CONF3, INF4, CONF9 e FEM10 destacaram os seguintes obstáculos respectivamente: o Instagram só mostra o que o usuário curte, a ferramenta patrocinado não tem o alcance que deveria, curtidas e comentários misturados e postagens que desaparecem devido a denúncias. A seguir, tem-se um relato que ilustra um desses problemas: 


\section{Quadro 7. Consolidação das dificuldades}

\begin{tabular}{|c|c|c|c|c|c|c|c|c|c|c|c|c|c|c|c|c|}
\hline Dificuldades & 1 & 2 & 3 & 4 & 5 & 6 & 7 & 8 & 9 & 10 & 11 & 12 & 13 & 14 & 15 & Total \\
\hline $\begin{array}{ll}\begin{array}{l}\text { Competição } \\
\text { preços }\end{array} & \text { por } \\
\end{array}$ & $\mathrm{X}$ & & & $\mathrm{X}$ & & & & & & $\mathrm{X}$ & & & $\mathrm{X}$ & & & 4 \\
\hline $\begin{array}{lr}\text { Vendas } & \text { que } \\
\text { dependem } & \text { de } \\
\text { terceiros } & \\
\end{array}$ & $\mathrm{X}$ & & & & & $\mathrm{X}$ & & $\mathrm{X}$ & & & & & & & & 3 \\
\hline $\begin{array}{l}\text { Público-alvo não } \\
\text { identificado }\end{array}$ & & & $\mathrm{X}$ & $\mathrm{X}$ & & & & & & & & & & & & 2 \\
\hline $\begin{array}{l}\text { Diminuição da fatia } \\
\text { de } \\
\text { mercado/Imitação } \\
\text { de produtos e } \\
\text { serviços }\end{array}$ & $\mathrm{X}$ & & & & & & & $\mathrm{X}$ & & & & & & & & 2 \\
\hline $\begin{array}{l}\text { Somente visão e } \\
\text { som }\end{array}$ & $\mathrm{X}$ & & $\mathrm{X}$ & $\mathrm{X}$ & & & & & & & $\mathrm{X}$ & & $\mathrm{X}$ & & & 5 \\
\hline $\begin{array}{l}\text { Funcionalidades } \\
\text { ruins }\end{array}$ & $\bar{X}$ & & $\bar{X}$ & $\mathrm{X}$ & & & & & $\mathrm{X}$ & $\mathrm{X}$ & & & & & & 5 \\
\hline $\begin{array}{l}\text { Experimentar } \\
\text { peças em casa }\end{array}$ & $\mathrm{X}$ & & & & & & & & & & & & & & & 1 \\
\hline $\begin{array}{l}\text { Conseguir } \\
\text { seguidores }\end{array}$ & & $\mathrm{X}$ & $x$ & $x$ & & & & $\mathrm{X}$ & & & $\mathrm{X}$ & $\mathrm{X}$ & $\mathrm{X}$ & $\mathrm{X}$ & & 7 \\
\hline $\begin{array}{l}\text { Falta de domínio } \\
\text { da ferramenta }\end{array}$ & & & & & & & & & & & & & & $\mathrm{X}$ & & 1 \\
\hline Sem dificuldades & & & & & $\mathrm{X}$ & & $\mathrm{X}$ & & & & & & & & $X$ & 3 \\
\hline Total & 6 & 1 & 4 & 5 & 1 & 1 & 1 & 3 & 1 & 1 & 2 & 1 & 3 & 2 & 1 & 33 \\
\hline
\end{tabular}

Fonte: elaborado pelas autoras com base nos dados coletados na pesquisa (2018).

...se eu tô promovendo a minha empresa, o meu Instagram, eu não quero que as pessoas que já sigam veja, eu queria que outras pessoas vissem e, às vezes, ele veicula a propaganda a alguém que já segue. (CONF3)

\section{Competição por preços}

Cozer (2007) pontua que a internet pode atuar como uma ferramenta que estimule a competição por preços. Afinal, na World Wide Web, os mais diferentes tipos de lojas dos mais variados seguimentos estão a apenas alguns cliques de distância do cliente, o que torna determinadas variáveis como, por exemplo, o preço, de suma importância para a organização. Tendo em vista esse cenário, 4 dos 15 informanteschave (FEM1, INF4, FEM10 e UNI13) comentaram que a competição por preços é um ponto negativo do Instagram, conforme é mostrado a seguir:

Mulher, os pontos negativos do Instagram às vezes eu acho que é a concorrência. (FEM10)

E você sabe que depois da crise, essa onda de empreendedorismo cresceu bastante né, e o Instagram tá sendo assim a válvula de escape de muitas pessoas, então você tem que colocar diferenciais... (UNI13)

Assim, observa-se que as dificuldades mais abordadas pelos entrevistados estão presentes na literatura sobre o empreendedorismo digital e sobre o social commerce. Todavia, o obstáculo funcionalidades ruins foi identificado por meio das falas dos entrevistados.

Ao se fazer um comparativo entre o Quadro 6 (Consolidação das motivações) e o Quadro 7, percebe-se que para todos os informantes-chave desta investigação empreender pelo Instagram tem mais benefícios do que dificuldades. 


\section{CONSIDERAÇÕES FINAIS}

O estudo objetivou averiguar o empreendedorismo informal digital por meio do Instagram no Nordeste. Para tanto, empregou-se o conhecimento acumulado sobre temáticas como empreendedorismo informal, empreendedorismo digital, empreendedorismo informal digital e social commerce para conhecer o que já havia sido estudado sobre perfil do empreendedor bem como suas motivações e dificuldades.

No que corresponde ao perfil, as informações encontradas nesta pesquisa não foram semelhantes a outras investigações sobre empreendedorismo informal ou empreendedorismo digital. Todavia, estão semelhantes aos resultados encontrados na pesquisa de Hung, Yu e Chiu (2018) sobre pequenos vendedores que utilizam scommerce em Taiwan. Dessa forma, conclui-se que apesar do social commerce ser um fenômeno com, aproximadamente, 13 anos de existência e que se tornou uma alternativa mais difundida entre os donos de negócio, especificamente no Instagram, há menos tempo ainda, o perfil dos vendedores que participaram desta pesquisa não é tão diversificado. Essa realidade revela que existe um público específico que vê o s-commerce como um local para empreender.

Quanto aos aspectos motivadores mais abordados desta investigação, é possível concluir que referem-se a pontos abordados na literatura sobre a economia informal, a economia digital e ao social commerce, evidenciando a importância de abordar uma temática em consonância com outras de forma a complementarem-se e enriquecer as pesquisas realizadas, demonstrando, nesse caso, que as motivações são variadas e inúmeras. É importante ressaltar que a motivação adesão de outras empresas não estava presente na literatura pesquisada e foi uma das mais citadas pelos entrevistados.

Conclui-se que, com relação às dificuldades para empreender, estas estão mais relacionadas a pontos negativos identificados na literatura relacionada à economia digital e ao social commerce, o que pode indicar que os respondentes desta pesquisa não percebem dificuldades quando se trata de atuar na informalidade. Destaca-se que os participantes perceberam mais motivações do que dificuldades nesse modelo de negócio.

Todavia, por se tratar de um modelo de negócio que começou a ganhar notoriedade em virtude da disseminação das redes sociais virtuais e dos smartphones, as pesquisas que tratam especificamente do social commerce no Instagram são escassas. Nesse cenário, durante a pesquisa foram identificadas motivações (adesão de outras empresas) e dificuldades (funcionalidades ruins) que não foram encontradas na literatura, bem como um ponto que na literatura pesquisada era tratado como uma dificuldade (simplicidade do modelo de negócio) e que durante as entrevistas foi identificado por alguns participantes como uma motivação.

Tais resultados mostram que há aspectos do social commerce no Instagram que precisam ser descobertos e aprofundados para gerar uma melhor compreensão e informações mais abrangentes e que permitam inferências que possam ultrapassar os próprios pesquisados.

O ponto que apresentou uma maior convergência de resultados relaciona-se ao perfil, em que muitos pontos se mantiveram constantes ao se comparar com a pesquisa de Hung, Yu e Chiu (2018), apesar dos participantes desta última residirem em Taiwan. 
O que pode ser observado nesta investigação é que esse modelo de negócio suporta as empresas participantes da pesquisa com cada uma de suas particularidades, sendo, dessa forma, altamente atrativo. Além de possibilitar que o empreendedor tenha acesso a um público-alvo que não seria possível de alcançar caso o negócio existisse apenas no ambiente off-line.

Entre as contribuições deste estudo, pode-se citar uma melhor compreensão sobre quem são os indivíduos que utilizam as redes sociais virtuais como uma plataforma de negócios, pois talvez seja possível prover a oportunidade de entender melhor alguns aspectos relacionados a esse modelo de negócio como, por exemplo, seus pontos positivos e negativos. Quanto às limitações, pontua-se a dificuldade de realizar entrevistas com pessoas de outros estados, visto que alguns não se sentiam à vontade em disponibilizar informações para alguém residente em outro estado e que eles nunca tiveram contato. Outra limitação relaciona-se a escassez de literatura sobre o social commerce em redes sociais virtuais para a construção desta pesquisa sendo, dessa forma, utilizada, em grande parte, literatura sobre temáticas relacionadas, o que dificultou um maior aprofundamento das discussões realizadas.

Para pesquisas futuras, recomenda-se replicar este estudo em outras regiões brasileiras para verificar se existem aspectos específicos influenciados pela cultura da região ou em outros segmentos de atuação como, por exemplo, o alimentício.

\section{REFERÊNCIAS}

ABBAS, S.; SINGH, A. K. Media Industry Trends and Dynamics: The Social Media Boom. Procedia-Social and Behavioral Sciences, v. 155, p. 147-152, 2014.

ADNEWS. Infográfico mostra perfil do usuários brasileiro no Instagram. Disponível em:< http://adnews.com.br/internet/infografico-mostra-perfil-do-usuario-brasileiro-noinstagram.html >. Acesso em: 18 jan. 2018.

AFRASIABI RAD, A.; BENYOUCEF, M. A model for understanding social commerce. Journal of Information Systems Applied Research, v. 4, n. 2, p. 6373, 2011.

ASSOCIAÇÃO BRASILEIRA DO VESTUÁRIO - ABRAVEST. Panorama do Setor. Disponível em:< http://abravest.org.br/site/abravest-2/panorama-do-setor/>. Acesso em: 24 jun. 2018.

BAGHDADI, Y. From e-commerce to social commerce: a framework to guide enabling cloud computing. Journal of theoretical and applied electronic commerce research, v. 8, n. 3, p. 12-38, 2013.

BARDIN, L. Análise de Conteúdo. São Paulo: Edições 70, 2011.

BUSALIM, A. HUSSIN, A. R. C. Understanding social commerce: A systematic literature review and directions for further research. International Journal of Information Management, v. 36, n. 6, p. 1075-1088, 2016. 
CALAIS, Isabela; Santos, Emerson Gomes dos. Barreiras no Uso Das Mídias Sociais Como Ferramentas de Marketing Digital Pelos Microempreendedores Individuais. In: VII Encontro de Marketing da ANPAD, p. 1-3, 2016.

COZER, M. T. S. Interação com Clientes Na Economia Digital: Um Estudo de Caso Múltiplo. Journal of Information Systems and Technology Management:

JISTEM, v. 4, n. 2, p. 217-234, 2007.

DAVIDSON, E.; VAAST, E. Digital entrepreneurship and its sociomaterial enactment. In: System Sciences (HICSS), 2010 43rd Hawaii International Conference on IEEE, 2010. p. 1-10.

DEMAILLY, C. The Business Impact of Social Networking. Disponível em: < https://www.business.att.com/content/whitepaper/WP-soc_17172_v3_11-10-08.pdf >. Acesso em: 18 jan. 2018.

DOMINGUES, A. A. Digital Entrepreneurship: a study on the use of technology as a business generation in educational startups. In: $14^{\text {th }}$ International Conference in Information Systems e Technology Management- CONTECSI, São Paulo, p. 5071-5078, 2017.

ERDOĞMUŞ, İ. E.; TATAR, Ş. B. Drivers of Social Commerce through Brand Engagement. In: 11 th International Strategic Management Conference, 2015. p. $189-195$.

FISCHER, E.; REUBER, A. R. Social interaction via new social media:(How) can interactions on Twitter affect effectual thinking and behavior?. Journal of business venturing, v. 26, n. 1, p. 1-18, 2011.

GASKELL, G. Entrevistas individuais e grupais. Pesquisa qualitativa com texto, imagem e som: um manual prático, v. 2, p. 64-89, 2002.

GASPARÉNIENÉ, L. et al. Level and sectors of digital shadow economy: the case of Lithuania. Entrepreneurship and sustainability issues, v. 4, n. 2, p. 183-197, 2016.

GASPARE்NIENE், L. et al. The methodology of digital shadow economy estimation. E+ M Ekonomie a Management, v. 20, n. 4, p. 20-33, 2017.

GASPARĖNIENĖ, L.; REMEIKIENE, R. Digital shadow economy: A critical review of the literature. Mediterranean Journal of Social Sciences, v. 6, n. 6 S5, p. 402-409, 2015.

GASPARĖNIENĖ, L.; REMEIKIENĖ, R.; SCHNEIDER, F. G. Concept, motives and channels of digital shadow economy: consumers' attitude. Journal of Business Economics and Management, v. 18, n. 2, p. 273-287, 2017. 
GENÇ, M.; ÖKSÜZ, B. A Fact or an Illusion: Effective Social Media usage of Female Entrepreneurs. Procedia-Social and Behavioral Sciences, v. 195, p. 293-300, 2015.

GIACOMIN, O. et al. Opportunity and/or necessity entrepreneurship? The impact of the socio-economic characteristics of entrepreneurs. 2011. Disponível em:< https://mpra.ub.uni-muenchen.de/29506/>. Acesso em: 3 maio 2018.

GODFREY, P. C. Toward a theory of the informal economy. Academy of Management Annals, v. 5, n. 1, p. 231-277, 2011.

GOLBECK, Jennifer. Introduction to Social Media Investigation: A Hands-on Approach. Syngress, 2015.

GOMES, R.de C. de O. Empreendedor X E-Empreendedor. RECADM, v. 2, n. 1, p. 1-17, 2003.

GRAY, D. E. Pesquisa no Mundo Real. 2 ed. Porto Alegre: Penso, 2012. HAJLI, M. A research framework for social commerce adoption. Information Management \& Computer Security, v. 21, n. 3, p. 144-154, 2013.

HULL, C. E. et al. Taking advantage of digital opportunities: a typology of digital entrepreneurship. International Journal of Networking and Virtual Organisations, v. 4, n. 3, p. 290-303, 2007.

HUNG, S.; YU, A.; CHIU, Y. Investigating the factors influencing small on-line vendors' intention to continue engaging in social commerce. Journal of

Organizational Computing and Electronic Commerce, v. 28, n. 1, p. 9-30, 2018.

Instagram. Press: Our Story. Disponível em:<https://instagram-press.com/ourstory/>. Acesso em: 19 jan. 2018.

$\mathrm{KIM}$, D. Under what conditions will social commerce business models survive?. Electronic Commerce Research and Applications, v. 12, n. 2, p. 69-77, 2013.

LATIFF, Z. A; SAFIEE, N. A. S. New Business Set Up for Branding Strategies on Social Media-Instagram. In: The Third Information Systems International Conference, p. $13-23,2015$.

LINDSEY-MULLIKIN, J.; BORIN, N. Why strategy is key for successful social media sales. Business Horizons, v. 60, n. 4, p. 473-482, 2017.

MARCONI, M. de A; LAKATOS, E. M. Fundamentos de Metodologia Científica. São Paulo: Atlas, 2017.

NAMBISAN, S. Digital entrepreneurship: Toward a digital technology perspective of entrepreneurship. Entrepreneurship Theory and Practice, v. 41, n. 6, p. 10291055, 2017. 
PARAISO, G. J. B. O E-COMMERCE NAS REDES SOCIAIS: estudo sobre os desdobramentos do comércio eletrônico na atualidade. Biblioteca on-line de Ciências da Comunicação, 2011.

PASCHOAL, A. de S. et al. Economia Informal: desafios ao estabelecimento de padrões de trabalho decente. Indivíduo, Sociedade e Autonomia: caminhos para a dignidade humana. Brasília: Editora da UNB, 2013.

PHUA, J.; JIN, S. V.; KIM, J. J. Gratifications of using Facebook, Twitter, Instagram, or Snapchat to follow brands: The moderating effect of social comparison, trust, tie strength, and network homophily on brand identification, brand engagement, brand commitment, and membership intention. Telematics and Informatics, v. 34, n. 1, p. 412-424, 2017.

SANCHEZ, M. J. Com 50 milhões de usuários, Brasil é segundo no ranking do Instagram. Disponível em:< http://www1.folha.uol.com.br/mercado/2017/10/1931057com-50-milhoes-de-usuarios-brasil-e-segundo-no-ranking-do-instagram.shtml>. Acesso em: 18 jan. 2018.

SCHNEIDER, F.; BUEHN, A. Estimating the size of the shadow economy: Methods, problems and open questions. ECONSTOR, 2013. Disponível em:<https://www.econstor.eu/bitstream/10419/97444/1/773137262.pdf >. Acesso em: 18 jan. 2018.

SEBRAE. Empreendedorismo Digital: Algumas boas perguntas para sua reflexão. Disponível em:< http://www.bibliotecas.sebrae.com.br/chronus/ARQUIVOS CHRONUS/bds/bds.nst/4 7D4BCB49B5EE0CB8325768F006C7FE0/\$File/NT00042F1A.pdf>. Acesso em: 7 out. 2017.

SOUZA, M. de; SCHOEFFEL, P. Panorama atual do social commerce no Brasil. REAVI-Revista Eletrônica do Alto Vale do Itajaí, v. 2, n. 2, p. 161-164, 2013.

SPC Brasil. Relatório de Pesquisa Mercado Informal. Disponível em:< https://www.spcbrasil.org.br/uploads/st imprensa/analise spc brasil mercado infor mal.pdf $>$. Acesso em: 18 jan. 2018.

VERGARA, S. Ct. Projetos e relatórios de pesquisa em Administração. 11.ed. São Paulo: Atlas, 2009. 94p.

VISENTINI, M.; CHAGAS, F.; BOBSIN, D. Análise Bibliométrica das Pesquisas sobre redes sociais virtuais publicadas em âmbito nacional. Anais do SEPE-Seminário de Ensino, Pesquisa e Extensão da UFFS, v. 5, 2015.

WANG, C.; ZHANG, P. The evolution of social commerce: The people, management, technology, and information dimensions. Communications of the Association for Information Systems, v. 31, n. 5, p. 1-23, 2012. 
WEBB, J. W. et al. Research on entrepreneurship in the informal economy: Framing a research agenda. Journal of Business Venturing, v. 28, n. 5, p. 598-614, 2013.

WELTER, F.; SMALLBONE, D.; POBOL, A. Entrepreneurial activity in the informal economy: a missing piece of the entrepreneurship jigsaw puzzle. Entrepreneurship \& Regional Development, v. 27, n. 5-6, p. 292-306, 2015.

WILLIAMS, C. C. Informal entrepreneurs and their motives: a gender perspective. International Journal of Gender and Entrepreneurship, v. 1, n. 3, p. 219-225, 2009.

ZHOU, L.; ZHANG, P.; ZIMMERMANN, H. Social commerce research: An integrated view. Electronic commerce research and applications, v. 12, n. 2, p. 61-68, 2013. 